\title{
Effect of ultrasound parameters for unilamellar liposome preparation
}

\author{
Raquel Silva, Helena Ferreira, Collin Little, Artur Cavaco-Paulo* \\ Dept. Textile Eng., University of Minho, 4800-058 Guimarães, Portugal
}

\section{A R T I C L E I N F O}

\section{Article history:}

Received 7 July 2009

Received in revised form 21 September

2009

Accepted 20 October 2009

Available online 24 October 2009

\section{Keywords:}

Liposome

Sonication

Reactor optimization

Photon-correlation spectroscopy

Zeta-potential measurements

\begin{abstract}
A B S T R A C T
In this study, it was investigated the effects of ultrasound, namely power input, distance from ultrasound tip to base of reactor and treatment time, in the formation of liposomes. Results indicate a dependence on cavitation events that are a function of power input, and consequently dependent on the position of the probe within the reaction vessel and the wave behaviour. Short treatment times are required to achieve nanosized vesicles in anti-nodal $(\lambda / 4 ; 19 \mathrm{~mm})$ reactor geometries. In this wave point the cavitation phenomenon is more pronounced when compared with the nodal point $(\lambda / 2 ; 38 \mathrm{~mm})$. Therefore, the consideration of the above parameters is vital if dependable and repeatable results are to be achieved.
\end{abstract}

(c) 2009 Elsevier B.V. All rights reserved.

\section{Introduction}

Liposome applications can been found in many different areas as biochemistry, molecular biology, food technology, pharmaceutical and medical. Each application requires vesicles with different characteristics, which will be dependent for example, on the material to be encapsulated, as well as on the different release properties [1-3]. Different methodologies are described in the literature to produce multi-lamellar vesicles (MLVs), large unilamellar vesicles (LUVs) and small unilamellar vesicles (SUVs) $[1,2,4,5]$. The use of ultrasound methods to produce LUVs and SUVs are widely reported in the literature [5-7]. However, the productions of these phospholipid vesicles are poorly reproducible, since that ultrasound experimental set-up is poorly described.

Ultrasound phenomena in liquid media enhance mass transports of their constituents in a non-homogeneous fashion allowing the fast formation of vesicles $[8,9]$. Several authors had pointed the fact that the most claimed ultrasound characteristics are in direct dependence of power input and duration of sonication effects [10-12]. However, the control of these two parameters still leaves the possibility of variation sound field intensity arising from the relationship between the frequency of ultrasound, position of probe tip from the base of the vessel and the phase of the sound wave upon reflection at the base. It is well known that ultrasound mechanical waves generate cavitation in liquids with the formation of local hot spots and free radicals $[13,14]$. Previous work, done by Little et al., has shown that variations of the ultrasound

\footnotetext{
* Corresponding author. Tel.: +351 253 510271; fax: +351253 510293

E-mail address: artur@det.uminho.pt (A. Cavaco-Paulo).
}

path-length had a marked effect on rates of temperature rise and radical production within the bulk solution [15]. Therefore, the power input, the duration of treatment and the position of the ultrasound source within the solution, will have an outcome on the ultrasound conditions imposed on the solution. This will affect the levels of hydroxyl radicals $(\cdot \mathrm{OH})$ generated in solution. In fact, the chemical effects of the cavitation bubble collapse, namely $\mathrm{OH}$ radical formation, are rarely considered in detriment of the extent of the tensile stresses imposed by ultrasound, which are usually reported [15].

The present work intends to show the need of control experimental set of operating parameters to engineer the characteristics of phospholipids vesicles. For that it was performed an extensive reactor characterization process. The methodology that was used explored the effects of the three parameters referred, namely power input, sonication time and depth (measure from the base of the vessel), in the production of hydroxyl radicals and consequently in the formation of vesicles. These conditions were related with lipid vesicle size, the polydispersity index (PDI) and surface charge (before and after sonication).

\section{Materials and methods}

\subsection{Materials}

\subsubsection{Reagents}

Sodium phosphate dibasic, monosodium phosphate, terephthalic acid, sodium hydroxide, chloroform and 1,2-dipalmitoylsn-glycerol-3-phosphocholine (DPPC) were purchased from Sigma Chemicals and used as supplied, without further purification. 


\subsubsection{Ultrasound equipment}

The experimental set-up used was composed of a probe type ultrasound source (20 kHz Sonics and Materials Vibracell CV 33) fitted with a $3 \mathrm{~mm}$ diameter titanium micro-tip. Power delivery was controlled as percentage amplitude (23\%, 30\% and 40\%). The reaction vessel was an open glass cell (diameter $19 \mathrm{~mm}$ and height $75 \mathrm{~mm}$ ), which contained $16 \mathrm{~mL}$ of sample solution.

\subsection{Methods}

\subsubsection{Calorimetry and dosimetry procedures}

The reactor was characterized via calorimetry and dosimetry by an adaptation of the previously published method [15]. Calorimetry measurements were performed within a custom made enclosure with temperature recorded via four wire ended k-type thermocouples (TCs), three positioned at the outer sides and one at the base of a glass vessel of the same type as that used for dosimetry and liposome formation. The TCs were interfaced with a Pico Technology TC-08 Thermocouple data logger connected to a computer with Pico Log software version R.33. The sonochemical reactor temperature was controlled via a thermo-stated water bath with a heat exchanger placed within a thermo jacket cell. The vessel was filled with $16 \mathrm{~mL}$ of deionised water and the probe activated for ninety seconds $(90 \mathrm{~s})$ constant ultrasound at the indicated power input settings. The initial temperature $\left(T_{i}\right)$ was taken from the average within the solution for $10 \mathrm{~s}$ prior to activation, and the final temperature $\left(T_{f}\right)$ the average in the final $40 \mathrm{~s}$ of sampling. Calorimetry was performed using deionised water and the calorific power of the reactor was determined from Eq. (1), where $E$ is the calculated energy $(J)$ to raise the water temperature, $\Delta T_{A V E}$ is equal to difference of the final and initial temperature $\left(T_{f}-T_{i} ; \mathrm{K}\right), m$ is the mass of $\mathrm{H}_{2} \mathrm{O}(\mathrm{kg})$ and $C_{p}$ is the heat capacity of $\mathrm{H}_{2} \mathrm{O}\left(4186 \mathrm{~J} \mathrm{~kg}^{-1} \mathrm{~K}^{-1}\right)$. The change in temperature $(\Delta T)$ from the initial to final levels was calculated for each TC position where $\Delta T=T_{f}-T_{i}$, values were averaged from the four TC positions to give $\Delta T_{A V E}$

$E=\Delta T_{A V E} \cdot m \cdot C_{p}$

Calorific power was subsequently converted to intensity (I) units of $\mathrm{W} \mathrm{cm}^{-2}$ using Eq. (2) where $\Delta t$ is the time of ultrasound activation and $\pi \cdot r^{2}$ the surface area of the micro-tip

$I=\frac{E}{\Delta t \cdot \pi \cdot r^{2}}$

A total sonication time of $90 \mathrm{~s}$ using the previously specified duty cycle was used at an indicated power input percentages of $23 \%, 30 \%$ and $40 \%$.

The dosimetry procedure was performed by the ultrasonic irradiation of buffered aqueous terephthalic acid (TA) solution [15]. This leads to the breakdown or sonolysis of the water, which results in the formation of hydroxyl $(\cdot \mathrm{OH})$ and hydrogen $\left(\mathrm{H}^{*}\right)$ radicals. The reaction is specific to $\mathrm{OH}$ radical and results in conversion of TA to 2-hydroxyl-terephthalic acid (HTA), which exhibits fluorescence under UV excitation and accounts for $35 \%$ of $\cdot \mathrm{OH}$ radical formation [10].

The detection of HTA was performed on a Shimadzu RF-1501 spectrofluoro-photometer, using an excitation wavelength of $314 \mathrm{~nm}$ and an emission wavelength of $425 \mathrm{~nm}$. Samples were taken $(2 \mathrm{~mL})$ in triplicate and returned after analysis. The HTA decay rate during the $15 \mathrm{~min}$ of incubation time was negligible. Fluorescence data was averaged and converted to $n \mathrm{~mol} \mathrm{~mL}^{-1} \mathrm{~s}^{-1}$ using the calibration curve of fluorescence vs HTA concentration (nmol mL ${ }^{-1}$ ).

The calorimetry and dosimetry procedures were based on the variations of the distance between the ultrasound tip and the base of the reaction chamber, shown as $x$ in Fig. 1. These distances vari-

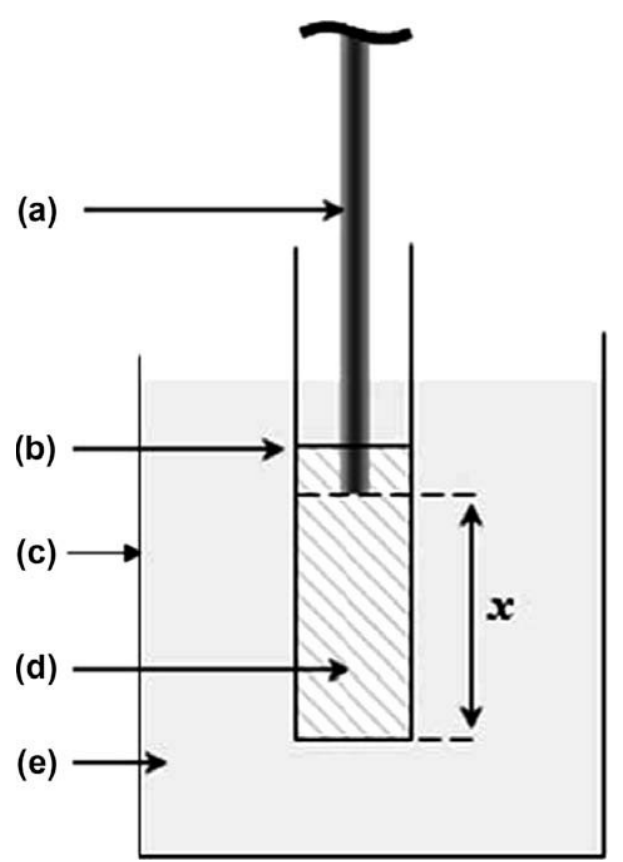

Fig. 1. Experimental set-up: (a) ultrasound probe ( $3 \mathrm{~mm}$ diameter); (b) glass vessel (diameter $19 \mathrm{~mm}$ and height $75 \mathrm{~mm}$ ); (c) jacketed vessel (diameter $130 \mathrm{~mm}$ and height $180 \mathrm{~mm}$ ); (d) lipid solution $(16 \mathrm{~mL}, 1500 \mu \mathrm{M})$; (e) temperature control bath $\left(50.0^{\circ} \mathrm{C}\right)$ and $(x)$ distance between ultrasound tip and base of the glass vessel.

ations were chosen based on a guideline wavelength. The Marczak equation (Eq. (3)) [16] gave us the value of the velocity of sound in pure water $(c)$, and therefore, it is possible to determine the wavelength according to the Eq. (4), where $T$ is the temperature in degrees Celsius and the $f$ the frequency in $\mathrm{kHz}$

$$
\begin{aligned}
c= & 1.402385 \times 10^{-3}+5.038813 T-5.799136 \times 10^{-2} T \\
& +3.287156 \times 10^{-4} T^{3}-1.398845 \times 10^{-6} T^{4}+2.787860 \\
& \times 10^{-9} T^{5} \\
\lambda= & c / f
\end{aligned}
$$

According to Eqs. (3) and (4) for $50{ }^{\circ} \mathrm{C}$ the wavelength was $77.1 \mathrm{~mm}$.

\subsubsection{Liposomes preparation}

Liposomes were prepared by the thin film hydration method as detailed by Ferreira et al. [17]. According to this method, a known amount of DPPC was dissolved in chloroform. The organic solvent was evaporated under a nitrogen stream and the residual traces of solvent were removed by a further evaporation for, at least, three hours under the same stream. The resulting dried lipid film was dispersed by the addition of phosphate buffer $(0.1 \mathrm{M}, \mathrm{pH} 7.4)$. These mixtures were then vortexed above their phase transition temperature $\left(41.4^{\circ} \mathrm{C}\right)$ to produce MLVs. MLVs suspension were sonicated at $50 \pm 1{ }^{\circ} \mathrm{C}$ to produce LUVs and was carried out with a total treatment of 21 min monitored in 3 min increments. A pulsed duty cycle of $8 \mathrm{~s}$ on, $2 \mathrm{~s}$ off was used for all the experiments with indicated power delivery of $23 \%, 30 \%$ and $40 \%$.

\subsubsection{Photon-correlation spectroscopy (PCS) and zeta-potential} measurements

The zeta-potential, the PDI and the size distribution of liposomes were determined at $\mathrm{pH} 7.4$ (phosphate buffer) and $50^{\circ} \mathrm{C}$ via dynamic light scattering (DLS) analysis using a Malvern zetasizer NS. 


\section{Results and discussion}

The reactor was characterized via calorimetry and dosimetry procedures, as described in Section 2.2.1, prior to testing the liposome behaviour to the sonication. These two procedures were made at $19 \mathrm{~mm}$ (anti-nodal point; $\lambda / 4$ ) and $38 \mathrm{~mm}$ (nodal point; $\lambda / 2$ ) of depth, which were calculated based on an estimated wavelength of $77.1 \mathrm{~mm}$. The nodal point is known as a point where the wave has the minimal amplitude. The opposite of a nodal point is an anti-nodal point, where the amplitude of the wave is maximum.

The calorimetry results are presented in Fig. 2. In this figure, it is possible to observe that the energy deposition for these two depths (19 and $38 \mathrm{~mm}$ ) increase with the power input. The highest value of input energy (about of $50 \mathrm{~W} \mathrm{~cm}^{-2}$ ) was obtained at $19 \mathrm{~mm}$ of depth and $40 \%$ of power input. Although, when it was used the $23 \%$ of power input at two different depths (19 and $38 \mathrm{~mm}$ ), it was obtained the same input energy inside of the reactor (about $15 \mathrm{~W} \mathrm{~cm}^{-2}$ ). After the calorimetry method it was performed the TA dosimeter, which is extensively used as an $\mathrm{OH}$ radical indicator $[11,12]$. The extent of the conversion of TA to HTA obtained in the dosimetry procedure is shown in Fig. 3. The behaviour at the $38 \mathrm{~mm}(\lambda / 2)$ position showed an almost linear production of hydroxyl radicals. Conversely, the $19 \mathrm{~mm}(\lambda / 4)$ position displayed a significant increase in hydroxyl radical production at $40 \%$ power input. The possible reason for this is that whilst cavitation bubble implosion is regarded as necessary for ${ }^{\circ} \mathrm{OH}$ radical formation, and is also a contributor of heat, other factors are present which contribute heat energy to the solution when conditions do not favor ${ }^{\circ} \mathrm{OH}$ radical production. These include cavitation bubble implosion of insufficient energy to form radicals, fluid friction within the bulk solution from the mixing effect, and friction between the bulk solution with the stationary boundary layer adjacent to the side of the vessel. These friction forces could continue to provide heat energy even when the differential in acoustic pressure is not enough to sustain effective cavitation [15]. After this characterization, it was possible to identify the minima and maxima hydroxyl radical activity points as occurring at $38 \mathrm{~mm}$ (nodal point) and $19 \mathrm{~mm}$ (anti-nodal point) positions, respectively.

The characterization described above is essential, once that the ultrasound can promote the hydrolysis and the oxidation of phospholipids, via the free radicals produced in the cavitation bubbles collapse. Additionally, high temperatures accelerate phosphocholine hydrolysis. Thus, during the sonication procedure, temperature should be controlled otherwise oxidation and hydrolysis reactions are favored $[18,19]$. However, according to Rabinovich-

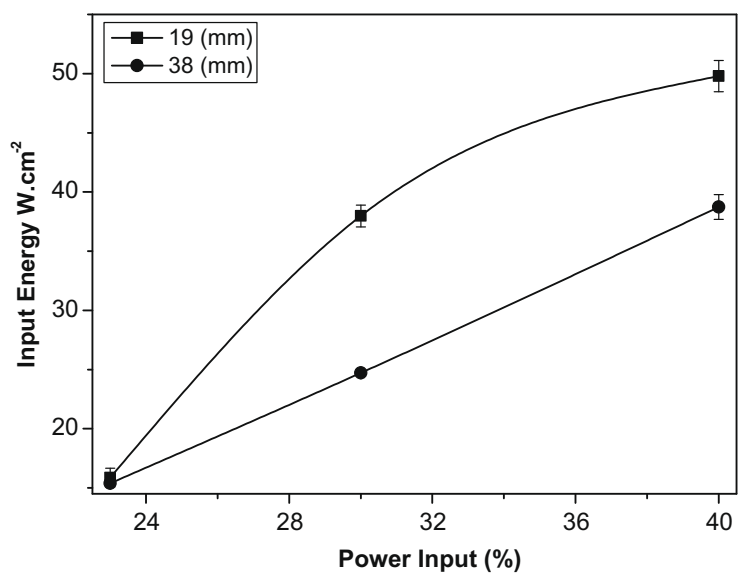

Fig. 2. Variation of measured input energy $\left(\mathrm{W} \mathrm{cm}^{-2}\right)$ with power input (\%), at different depths (19 and $38 \mathrm{~mm}$ ).
Guilatt et al. [20] a temperature of $50{ }^{\circ} \mathrm{C}$ over $24 \mathrm{~h}$ induces only $1.6 \%$ of phosphocholine hydrolysis. In this context, in order to minimize the hydrolysis, the temperature was controlled during all the experiment using a thermo-stated bath and the sonication was carried out in time intervals of $3 \mathrm{~min}$. Therefore, in our working conditions this hydrolysis should be negligible.

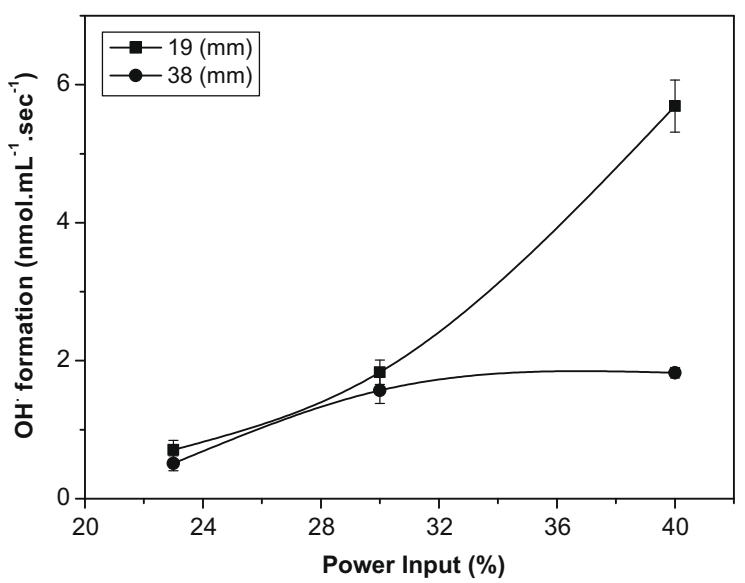

Fig. 3. Variation of rate of $\mathrm{OH}$ radical formation $\left(\mathrm{nmol} \mathrm{mL}^{-1} \mathrm{~s}^{-1}\right)$ with power input (\%), at different depths (19 and $38 \mathrm{~mm}$ ).
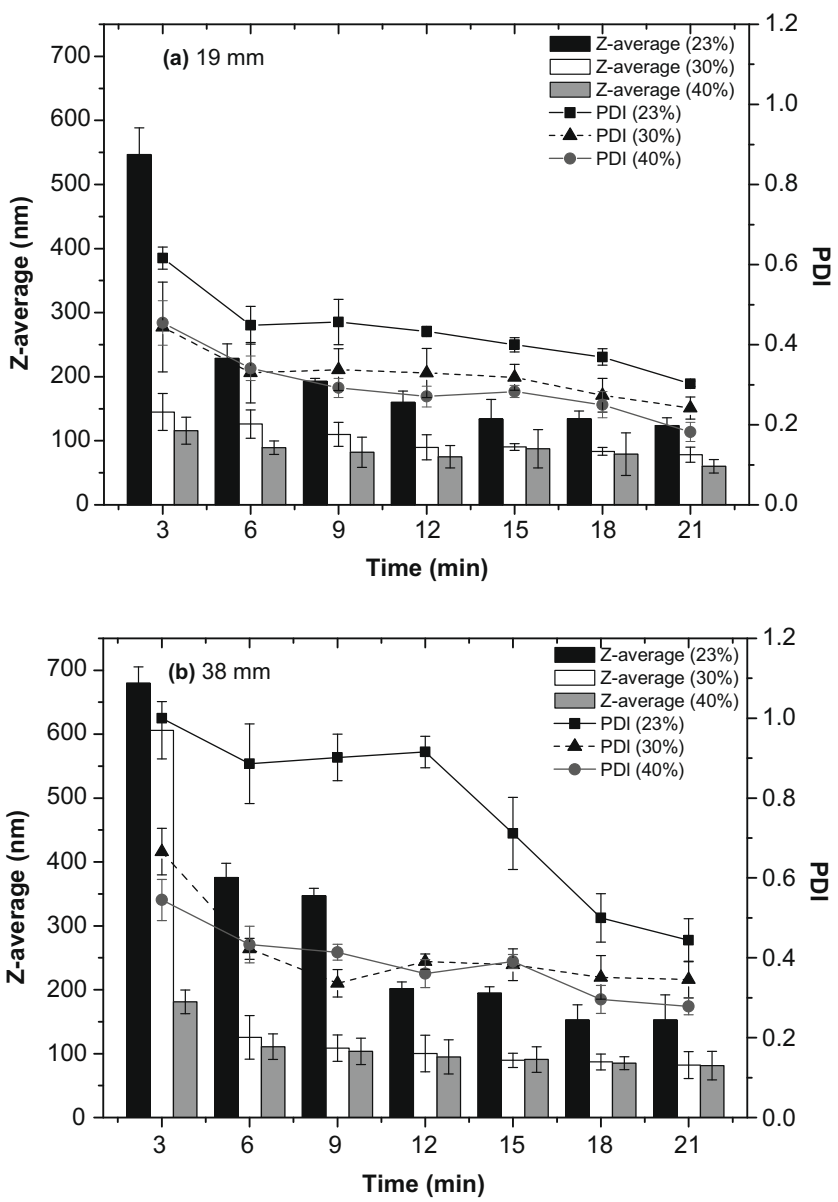

Fig. 4. Effect of sonication on DPPC liposomes ( $1500 \mu \mathrm{M})$ sizes using $19 \mathrm{~mm}$ (a) and $38 \mathrm{~mm}$ (b) of depth, applying different amplitudes (23\%, 30\%, 40\%) after 3, 6, 9, 12, 15,18 and $21 \mathrm{~min}$, at $50^{\circ} \mathrm{C}$ and $\mathrm{pH} 7.4$. 
a

Size Distribution by Volume

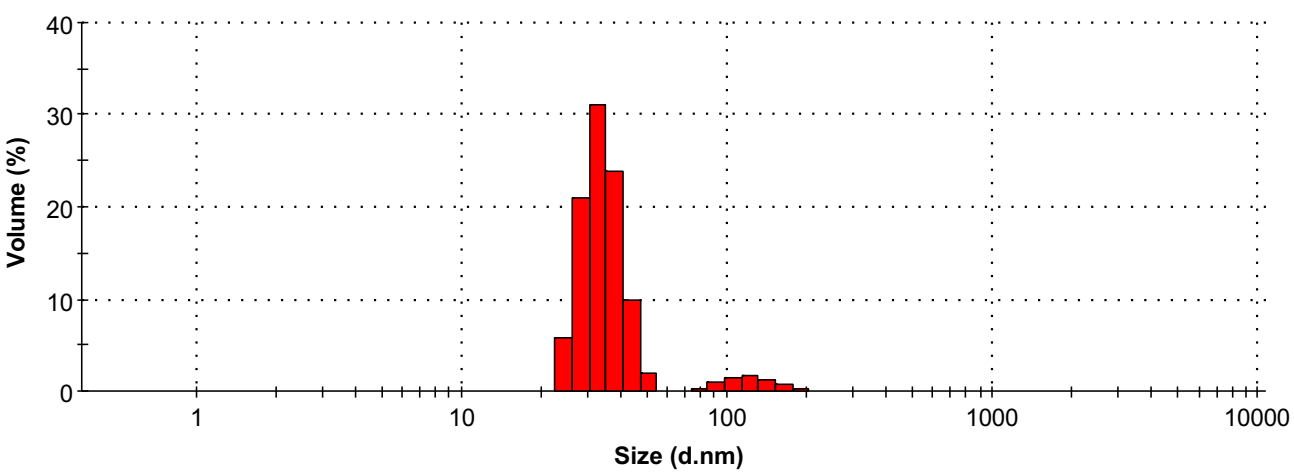

b

Size Distribution by Volume

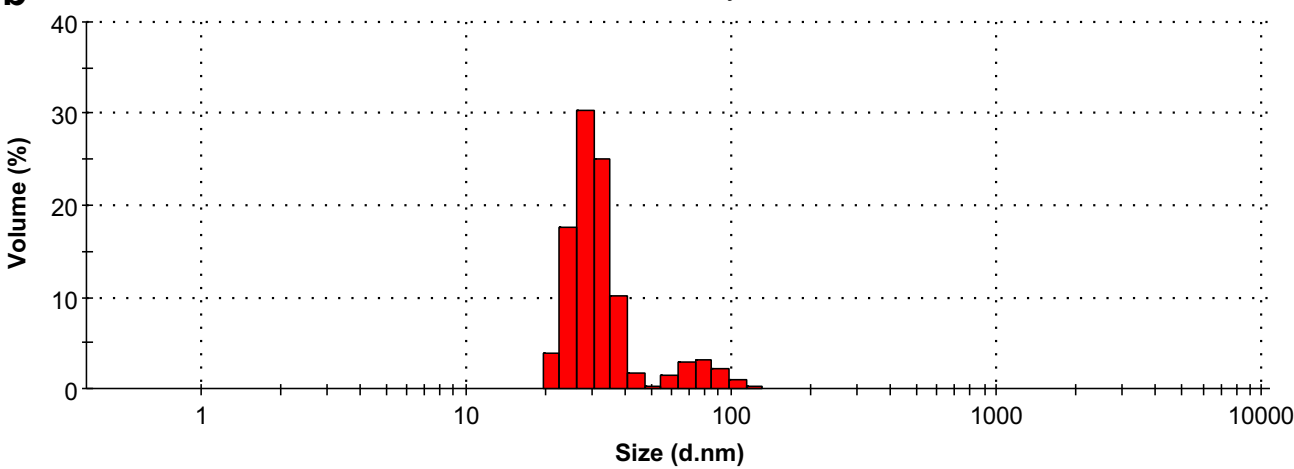

Fig. 5. Size distribution of liposomes $(1500 \mu \mathrm{M})$ using $19 \mathrm{~mm}$ (a) and $38 \mathrm{~mm}$ (b) of depth, after $21 \mathrm{~min}$ of sonication, with $40 \%$ of amplitude, at $50{ }^{\circ} \mathrm{C}$ and $\mathrm{pH} 7.4$.

a

Size Distribution by Volume
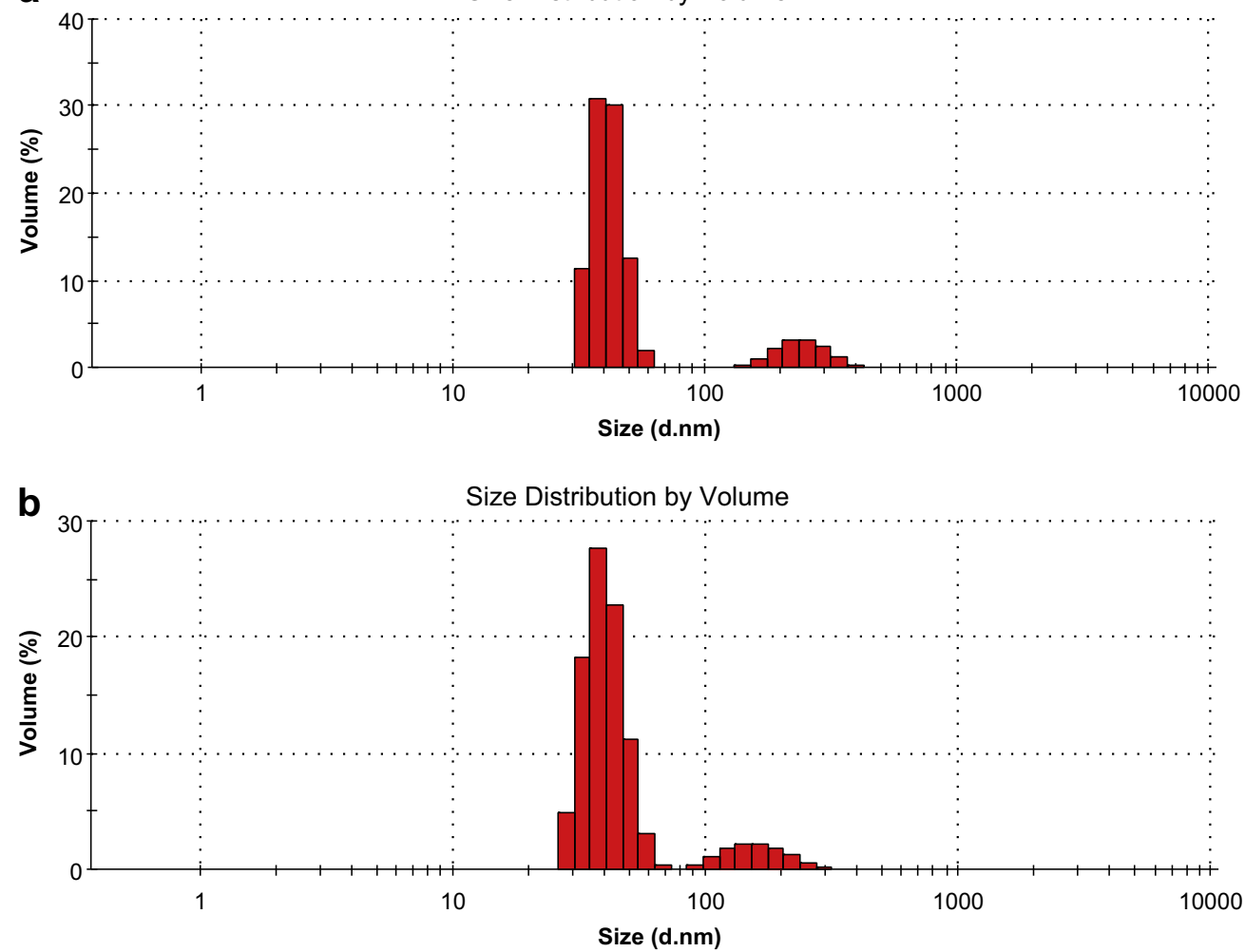

Fig. 6. Size distribution of liposomes $(1500 \mu \mathrm{M})$ using $19 \mathrm{~mm}$ (a) and $38 \mathrm{~mm}$ (b) of depth, after 21 min of sonication, with $23 \%$ of amplitude, at $50{ }^{\circ} \mathrm{C}$ and $\mathrm{pH} 7.4$. 
Afterwards, the ultrasonic treatment of the liposomes was carried out at amplitudes of $23 \%, 30 \%$ and $40 \%$, using the depths of 38 and $19 \mathrm{~mm}$, measured from the base of the vessel. The variation of the vesicles size with sonication time, at different fixed sonication powers and different depths, was analyzed by DLS.

Size distribution is a crucial parameter for the characterization of liposomes and can be weighted by number, surface area, volume or any other property of the particle being measured. These different measurements are dependable of the liposomes applications. Liposomal delivery of an encapsulated hydrophilic drug, for example, is best described by a volume-weighted histogram to determine the liposome size at which most of the drug is carried. Delivery of a membrane-bound molecule may be better described by a surface-area weighted histogram [7]. In this work, the size of liposomes was measured in terms of volume, so these liposomes can be used as vehicle for controlled release [21]. Fig. 4 shows the vesicle size, after increasing sonication times and using constant sonication amplitudes: $23 \%, 30 \%$ and $40 \%$, for the system containing $1500 \mu \mathrm{M}$ of DPPC. This figure shows a decrease of the particle size with the increase of the sonication time, until a plateau size was obtained after $21 \mathrm{~min}$ of sonication. These results also show that the vesicle sizes decreased when sonication amplitude increased.

In addition, using different sonication times and different depths, a difference in the sizes were observed. Considering a constant sonication time and amplitude, a higher value of liposome sizes were observed when the treatment was made at $38 \mathrm{~mm}$. On the other hand, at the anti-nodal point $(19 \mathrm{~mm})$ the cavitation phenomenon is more pronounced promoting a higher hydroxyl radical formation. These phenomena could affect the composition of samples and the formation of vesicles with lower sizes. However, in the nodal point $(38 \mathrm{~mm})$ the size obtained was not so different, after $21 \mathrm{~min}$ of treatment, with the advantage to decrease the possibility of phospholipid oxidation since at this depth the -OH radical production is much lower. Fig. 4 also shows that using higher amplitude it was possible to obtain a decrease in PDI. In fact, the size and PDI decreased as the higher power exerts greater shear forces within the solution. The greater extent of streaming from the ultrasound source promotes higher mixing of the solution and consequently more homogeneity. Therefore, at $19 \mathrm{~mm}$ and after 21 min of treatment a drop in the physical size and PDl was observed. However, at $38 \mathrm{~mm}$ the difference of size was not so significant and the possibility of occurring oxidative reactions is lower. This is very important when it is used polyunsaturated phospholipids, because they are easily oxidised. In Figs. 5 and 6 it can be observed two different sizes of population. Current theories postulate that sonication, as other methods of liposome formation, randomly fragment MLVs into what are termed LUVs $[1,22]$. These disc-like fragments are thought to fold up into thermodynamically stable liposomes [23]. Alternatively, tiny unstable liposomes, formed during sonication, may fuse together to form slightly larger, stable liposomes [24,25].

The determinations of zeta-potential were made before and after sonication. After the measurements it was verified that the potential surface of liposomes did not change significantly by the use of ultrasound $(\approx 3.90$ and $\approx 3.24 \mathrm{mV}$, before and after ultrasound, respectively).

\section{Conclusions}

The results of this work show the importance of reactor characterization to attain the control of liposome sizes using an ultrasonic probe system. It was considered that the three principal factors of ultrasound which could influence the ranges of size and zeta-po- tential of liposomes are: depth, power input and extent of treatment. Indeed, these factors that could influence the cavitation phenomenon have an impact on the rate and structure of the vesicles formed. At $19 \mathrm{~mm}$ of depth, $40 \%$ of amplitude and $21 \mathrm{~min}$ of treatment, carried out in time intervals of $3 \mathrm{~min}$, it is possible to obtain a more homogeneous population of nanosized vesicles than $38 \mathrm{~mm}$. These two positions are of importance when using ultrasound for the breakup of multi-lamellar liposome layer stuff, in particular the position at which constructive interference (anti-nodal point; $19 \mathrm{~mm}$ ) occurs as this maximises cavitation events and associated phenomena.

These findings seem to indicate the usefulness of the ultrasound method to obtain unilamellar liposomes, particularly when the parameters are controlled.

\section{References}

[1] D.D. Lasic, Liposomes-from Physics to Applications, Elsevier, New York, 1998.

[2] S. Vemuri, C.T. Rhodes, Preparation and characterization of liposomes as therapeutic delivery systems: a review, Pharm. Acta Helv. 1994 (1995) 95-111.

[3] K.A. Edwards, A.J. Baeumner, Analysis of liposomes, Talanta 68 (2006) 14321441.

[4] A. Gómez-Hens, J.M. Fernández-Romero, The role of liposomes in analytical processes, Trends Anal. Chem. 24 (2005) 9-19.

[5] R.R.C. New, Liposomes - A Practical Approach, Oxford University Press, New York, 1990.

[6] M. Kiyoshi, S. Yuklo, H. Masao, Formation and mechanical stability of phospholipid vesicles, Membrane 17 (1992) 257-262.

[7] J. Pereira-Lachataignerais, R. Pons, P. Panizza, L. Courbin, J. Rouch, O. López, Study and formation of vesicles systems with low polydispersity index by ultrasound method, Chem. Phys. Lipid 140 (2006) 88-97.

[8] C. Basto, T. Tzanov, A. Cavaco-Paulo, Combined ultrasound-laccase assisted bleaching of cotton, Ultrason. Sonochem. 14 (2007) 350-354.

[9] A. Kumar, P.R. Gogate, A.B. Pandit, H. Delmas, A.M. Wilhelm, Gas-Liquid mass transfer studies in sonochemical reactors, Ind. Eng. Chem. Res. 43 (2004) 1812-1819.

[10] T.J. Mason, D. Peters, Practical Sonochemistry: Uses and Applications of Ultrasound, Horwood Publishing, Chischester, West Sussex, UK, 2002.

[11] T.J. Mason, J.P. Lorimer, D.M. Bates, Y. Zhao, Dosimetry in sonochemistry: the use of aqueous terephthalate ion as a fluorescence monitor, Ultrason. Sonochem. 1 (1994) 91-95

[12] X. Fang, G. Mark, C. von Sonntag, OH radical formation by ultrasound in aqueous solutions. Part I: the chemistry underlying the terephthalate dosimeter, Ultrason. Sonochem. 3 (1996) 57-63.

[13] J. Rae, M. Ashokkumar, O. Eulaerts, C. von Sonntag, J. Reisse, F. Grieser Estimation of ultrasound induced cavitation bubble temperatures in aqueous solutions, Ultrason. Sonochem. 12 (2005) 325-329.

[14] M. Ashokkumar, J. Lee, S. Kentish, F. Grieser, Bubbles in an acoustic field: an overview, Ultrason. Sonochem. 14 (2007) 470-475.

[15] C. Little, M. El-Sharif, M.J. Hepher, The effect of solution level on calorific and dosimetric results in a $70 \mathrm{kHz}$ tower type sonochemical reactor, Ultrason. Sonochem. 14 (2007) 375-379.

[16] W. Marczak, Water as a standard in the measurements of speed of sound in liquids, J. Acoust. Soc. Am. 102 (1997) 2776-2779.

[17] H. Ferreira, M. Lúcio, J. Lima, C. Matos, S. Reis, Interaction of clonixin with EPC liposomes used as membrane model, J. Pharm. Sci. 94 (2005) 1277-1287.

[18] R. Almog, R. Forward, C. Samsonoff, Stability of sonicated aqueous suspensions of phospholipids under air, Chem. Phys. Lipid 60 (1991) 93-99.

[19] C. Genot, B. Métro, M. Viau, B. Bouchet, Characterization and stability during storage of liposomes made of muscle phospholipids, Lebensm.-Wiss. Technol. 32 (1999) 167-174.

[20] L. Rabinovich-Guilatt, C. Dubernet, K. Gaudin, G. Lambert, P. Couvreur, P. Chaminade, Phospholipid hydrolysis in a pharmaceutical emulsion assessed by physicochemical parameters and new analytical method, Eur. J. Pharm. Biopharm. 61 (2005) 69-76.

[21] R. Silva, C. Little, H. Ferreira, A. Cavaco-Paulo, Incorporation of peptides in phospholipid aggregates using ultrasound, Ultrason. Sonochem. 15 (2008) 1026-1032.

[22] B.A. Korgel, J.H. van Zanten, H.G. Monbouquette, Vesicle size distributions measured by flow field-flow fractionation coupled with multiangle light scattering, Biophys. J. 74 (1998) 3264-3272.

[23] P. Fromherz, D. Ruppel, Lipid vesicle formation - the transition from open disks to closed shells, FEBS Lett. 179 (1985) 155-159.

[24] J. Lasch, V. Weissig, M. Brandl, Preparation of liposomes, in: Liposomes: A Practical Approach, Oxford University Press, 2003, pp. 3-27.

[25] M. Brandl, D. Bachmann, M. Dreschler, K. Bauer, Liposome preparation using high-pressure homogenizers, in: Liposome Technology: Liposome Preparation and Related Techniques, CRC Press, 1993, pp. 49-65. 